\title{
Disempowering Mindfulness: Reflections on Discovering the Veils of Power in Well-Being and Good Intentions
}

\author{
Everardo Carvajal
}

\begin{abstract}
Despite the widespread popularity of mindfulness as a wellness intervention strategy across educational levels, its proponents are susceptible to countering the intended area of improvement. This article recounts the cumulative reflections of an educator and his attempts to implement mindfulness into high school classes at the Los Angeles County Jail. Beginning with a layout of the physical and social settings, the article examines the ways that unconsciously practicing mindfulness will counter and potentially negate the possible benefits of mindful practice.
\end{abstract}

\section{Disempowering Mindfulness: Reflections on Discovering the Veils of Power in Good Intentions}

Mindfulness, in varying forms, has gained popularity as a wellness intervention, and its champions have employed mindful practices in settings ranging from clinical treatment to K-12 education (Davis, 2012; Kabat-Zinn, 2003; Keng, Smoski, \& Robins, 2011). My aim here is to recount and share my experience cultivating a mindful practice with students in the Los Angeles County Jail. Particularly, I share how a non-mindful attempt at mindfulness inadvertently led me astray. These insights were refined over my doctoral studies as my views developed through courses on educational equity, accountability, diversity, learning, and pedagogy. I begin by explaining how the meta-moment fits into my school's role and classroom routine. Then, I expose some of my misguided attempts to implement mindfulness as a tool for my students' overall well-being.

Mindfulness ought to be defined before moving further. By mindfulness, I defer to Kabat-Zinn's (2003) intentional focus on attention as a deep reflection on the nature of human experience. This rather complex sounding description is sometimes reduced to and understood as meditation. As I have attempted to refer to and teach mindfulness, it is a way for one to focus thoughts and attention towards present-moment circumstances. For example, I have encouraged students to think of the mind as a dynamic thought train that can learn to slow down through deliberate attention and focus on real-time circumstances. This is often relevant given that students' attention in the classroom often needs to be guided away from the many stressful circumstances of life in addition to the extenuating context of incarceration. My goal has always been to offer the practice as a start of class for students to begin the day with a greater focus on school and learning. My ulterior motive, one I have often shared, is that students learn and are repeatedly modeled a tool to leverage against their life circumstances as an alternative to self-destructive behavior. This way, even if a student were to only attend our school for one 
week, he or she would be exposed to a potential coping tool that demonstrates a healthier alternative to the types of behaviors many of my students have become accustomed to.

Our school provides a second or third chance for adult students to earn a high school diploma. Additionally, through various channels, students are aligned with relevant resources in the form of employment, housing, and addiction treatment. One particular specialty of the school, however, is its series of life skills courses, which I have now taught for six years. My life skills course targets community reintegration based on what research has indicated as common (Bloom, Owen, \& Covington, 2005) needs of incarcerated adults.

The meta-moment is one of several components advanced by RULER's comprehensive emotional intelligence curriculum (Nathanson, Rivers, Flynn, \& Brackett, 2016). Although there are other components of the program, I implemented a modified form of the meta-moment. Once the class is seated, and before moving further into the lesson, students pause for three minutes to practice the metamoment. During our meta-moments, students sit quietly, five per table, inhaling deeply with closed eyes while awash with audible clutter of radio transmissions, speakerphones, running toilets, and slamming steel doors. This is always followed by a flexible five-minute group discussion.

I introduced the meta-moment four years ago to help students morph the curious climate of a jail into an atmosphere learning and collaboration. I adopted the meta-moment hoping to give our students a practical and immediate tool for their circumstances. It was important to me that we institutionalize a space to pause long enough to observe inward. Our version of the practice is different in that it concludes with a formal group discussion about students' internal observations. Reflections elicit emotions that range from remorse to shame and guilt and to optimism or hope. The combination of deep reflection, insightful assignments, and new insight sometimes triggers students to leave the dorm because of what they perceive to be superfluous stress. This gives me reason to believe the meta-moment is especially key for students who are also in highly vulnerable circumstances like incarceration. Further, despite the breadth of available publications and approaches to mindfulness, meditation, and similar practices, teachers and students will benefit by avoiding my mistakes.

\section{Purpose}

I began the meta-moment with a single purpose in mind. I believed that my students would gain more from class if they could ready themselves in the first few minutes. Later, I struggled with my unilateral definition. That is, instead of allowing the students to make and create meaning with the practice, I excluded students from the meaning making that otherwise occurred. For instance, when I made the case that it was for calming one's self, I was predisposing the naturally nervous student for failure. Furthermore, the student would have been set up for failure because the uneven personal circumstances were so wide ranging that few were predisposed to easily adapt the practice as it was narrowly defined. The point is that rigidly narrowing a successful moment or reflection is exclusionary and, by definition, counters the nature of a mindful practice. Alternatively, allowing students to discover and create meaning 
of the practice ensures the nature becomes inclusionary by observing a more expansive notion of success relative to students' dispositions.

Regrettably, I insinuated that reflection occurred in only one way. And, if students failed to share a reflection that matched my expectations, I acted quickly to summarize their share and call on the next student. This also led me to anticipate a student's reflection so that, if it started turning in a direction I believed was wrong, I shut the student down and did not call on the student during later discussions. I believed the reflection briefly exposed whether the student observed internal dialogue and connected to his or her emotional disposition throughout the momentary self-connection. However, a mindful approach would not force a particular style of reflection, especially considering the diverse circumstances of a large class. I also struggled with wanting to correct students on why they failed to settle into a restful state, dismissing the ambient noise or the environmental and emotional discomfort of incarceration. I justified my silencing on the rare occasion that a student would snipe criticisms towards the custody staff or to prevent student monologues that resembled religious testimony. I was oblivious to the climate I created by seeking a specific type of reflection, and I failed to notice this until one student's uncommon reflection led to her tears and sobbing about how she regretted setting her partner on fire.

After nearly two years of practice, it occurred to me that I had narrowly framed the meta-moments' purpose and unilaterally held the power to define it. I cut off students for their seemingly off-track share. I shut them down and politely informed them that the class was not a venting forum. I told students that the meta-moment was not a confessional. Most likely, your classrooms contrast sharply versus a jail; however, I suspect the difference of social environments is a matter of degree and not of kind. In other words, your students are not likely to be in jail, but they are likely to struggle with how to share, deciding what is shareworthy or whether their thoughts ought to be publicly vented.

The facilitator's preconceived intentions have the potential to sap motivations from the reluctantly sharing student. Later, the facilitator, as I did, may wonder why the student is not motivated to complete assignments. Lisa Delpit (1988) wrote about the silenced dialogue and how the dynamics of power unfold through a teacher's policies and practices. I regret that I have done some silencing. In circumstances like these, I learned that mindful practice has the ability to elicit powerful feelings and set a stage for selfawareness, self-expression, and at times, self-growth. My point is, encourage reflection on the unseen influence of power bound up with asking students to reflect and share. This may better help you navigate the discussions emerging from your students' attempts at mindfulness.

\section{$\operatorname{Process}(\mathrm{es})$}

In my attempts to advance mindful practices, I failed to be open to the multitude of processes that could expose students to their inner dialogues. This became progressively clearer with practice as the plurality of processes unfolded as more classes practiced the meta-moment. For example, in the first year, I chose

not to ask students to close their eyes during the meta-moment. This would have required a high level of student trust given our open bay classroom and class of 50 to 60 students. Alternatively, I began by asking 
students to breathe and focus on their bodies for the three minutes. After practicing for about a year, I realized that, by making all students focus on their bodies, I limited their experiences. After reluctantly acknowledging these repeated examples, I introduced alternate methods as students continued to reflect on which methods yielded useful results. Some were responsive to the focus on breathing, others observed results by focusing on sound, and some found that a visual focus facilitated access to their inner thoughts. Only after the repeated practice and student reflection did I gradually realize that my students have infinite access points to self-reflection.

\section{Knowing}

I admit using mindfulness as an exercise in expelling an unwanted element of a student, such as a low interest in work, excessive talking, or lack of focus. Angela Valenzuela (2010) termed this approach as "subtractive schooling" and cautioned about this deficit-based practice. Only later did I understand the dynamics of power as expressed through demarcation of knowledge and how, beneath the surface, power is asserted in the process. This became especially clear after reflecting on how I expected students to conclude a specific insight about themselves and their real problems instead of valuing their unique conclusions.

I assumed that the meta-moment would necessarily reveal students' internal dialogue. I also misplaced my focus on students being able to reproduce the language of the meta-moment: calming the mind, observing the thoughts, observing the sensation of experience within them. In fact, students quickly excelled in the language, yet I mistakenly assumed that I knew what students would see about themselves by pausing for the meta-moment. For instance, during reflection, I would call on student after student and assume their use of the buzzwords were indicators that they fully understood. On the other end of the spectrum, I believed that, since students could not express themselves with the jargon, they must have lacked the effort we all had put forth. I failed to think about how difficult it would be for someone to articulate an insight they may have previously reserved for only themselves. In short, I identified use of jargon as proof of comprehension, and I saw communication struggles as ignorance and lack of effort. Both were wrong in ways other than mindfulness, though these insights only unfolded sporadically as students were able to express their insights during other classroom interactions.

Aside from the discussed dimension of power, I now understand the subversive nature of rigidly defining and deciding whether and what students ought to know. I no longer see the meta-moments as a tool to remove something from my students for them to access their internal worlds. Now, I aim to value students' gained insights no matter how far they may be from my anticipated student revelation. This means I no longer need to think about whether a student got it or not. Instead, I am now free to recognize that, despite my wish for students to identify some major internal discord, I can pause and recognize their insights as valuable self-knowledge. I have learned to leave room for students to know, for their insights to be true, and for my intentions for their knowledge to go unsatisfied. The temptation to tell students what they do not know is powerful, but encouraging students to value their preexistent insight is more powerful. 
Thus, my rigid practice limited my access to the flexible nature of mindful practice. I now have a broader respect for students' perspectives, purpose, and insight, all of which contributes to what Matsumura, Slater, and Crosson (2008) call a "positive classroom climate" (p. 295). In this way, creating a supportive learning environment is not magic, nor is it skill. It is the result of a dynamic interplay that requires thoughtfulness, openness, and flexibility.

\section{References}

Bloom, B. E., Owen, B. A., \& Covington, S. (2005). Gender-responsive strategies for women offenders: A summary of research, practice, and guiding principles for women offenders. US Department of Justice, National Institute of Corrections.

Davis, T. S. (2012). Mindfulness-based approaches and their potential for educational psychology practice. Educational Psychology in Practice, 28(1), 31-46.

Delpit, L. D. (1988). The silenced dialogue: Power and pedagogy in educating other people's children. Harvard Educational Review, 58(3), 280-298.

Kabat-Zinn, J. (2003). Mindfulness-based interventions in context: Past, present, and future. Clinical Psychology: Science and Practice, 10(2), 144-156.

Keng, S. L., Smoski, M. J., \& Robins, C. J. (2011). Effects of mindfulness on psychological health: A review of empirical studies. Clinical Psychology Review, 31(6), 1041-1056.

Matsumura, L. C., Slater, S. C., \& Crosson, A. (2008). Classroom climate, rigorous instruction and curriculum, and students' interactions in urban middle schools. Elementary School Journal, 108, 293312.

Nathanson, L., Rivers, S. E., Flynn, L. M., \& Brackett, M. A. (2016). Creating emotionally intelligent schools with RULER. Emotion Review, 8(4), 305-310.

Valenzuela, A. (2010). Subtractive schooling: US-Mexican youth and the politics of caring. Suny Press.

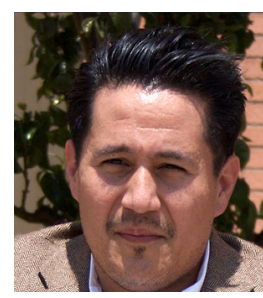

Everardo Carvajal is a doctoral student at the University of Southern California's Rossier School of Education with a focus on Educational Psychology. His research and teaching interests include teacher ideology, classroom climate, educational equity, non-cognitive skills, and alternative learning environments. For the past eight years, he has worked in several correctional education projects and is currently responsible for operating a high school in the Los Angeles County Jail. He has worked with local and state law enforcement officials as a teacher, curriculum developer and site director. He is now working on a project to embed mindfulness practices throughout the school. 